\title{
Health, physiology, and behavior of dairy calves reared on 4 different substrates
}

\author{
M. A. Sutherland, ${ }^{1}$ G. M. Worth, ${ }^{2}$ C. Cameron, C. M. Ross, and D. Rapp \\ AgResearch Ltd., Ruakura Research Centre, Hamilton 3214, New Zealand
}

\begin{abstract}
The objective of this study was to compare the health, physiology, and behavior of group-housed calves reared on wood shavings with those reared on alternative surfaces. At 1 wk of age, 80 calves were moved into 1 of 20 experimental pens $(\mathrm{n}=4$ calves/pen) where they remained until 6 wk of age. Pens had floors covered with pea gravel (PG), rubber chip (RC), sand (SA), or wood shavings (WS; $\mathrm{n}=5$ pens/substrate). Body weight, cleanliness, health, and skin surface and vaginal temperature were recorded at 1,3 , and $6 \mathrm{wk}$ of age. Escherichia coli numbers were assessed on the skin surface of the shoulder and in the feces of calves at 3 and 6 wk of age. Blood samples were taken at 1,3, and 6 wk of age to measure hematological values and cortisol, IgG, and lactate concentrations. Behaviors (lying, running, and self-grooming) were recorded in the home pen at 1, 3, and 6 wk of age using video recorders and accelerometer data loggers. At 6 wk of age, calves were tested individually in an arena test and behavior was recorded continuously for $20 \mathrm{~min}$. Body weight did not differ among calves reared on PG, RC, SA, or WS, regardless of age. All calves were clean and no calves displayed any signs of lameness, leg lesions, or injuries at wk 1, 3, or 6 , regardless of substrate. The number of $E$. coli recovered from a surface area of $100 \mathrm{~cm}^{2}$ on the shoulder of each calf was affected by rearing substrate, with more $E$. coli recovered from calves reared on WS than PG, RC, or SA at 3 and 6 wk of age. Fecal E. coli counts were not affected by rearing substrate at 3 or 6 wk of age. Over the entire study period, calves reared on PG and SA had lower skin temperatures than calves reared on $\mathrm{RC}$ or WS, but skin temperature was similar between calves reared on PG and SA. However, vaginal temperature did not differ among calves reared on different substrates at 1, 3, or 6 wk of age. Hematology values and cortisol, IgG, and lactate concentrations of
\end{abstract}

Received September 29, 2016.

Accepted November 21, 2016.

${ }^{1}$ Corresponding author: mhairi.sutherland@agresearch.co.nz

${ }^{2}$ Present address: LIC, Private Bag 3016, Hamilton 3240, New Zealand. calves were similar among rearing substrates over the 6 -wk study period. In the home pen, rearing substrate did not influence time spent lying; however, calves reared on WS performed more lying bouts than calves reared on PG or SA. In addition, rearing substrate did not influence the time calves spent running; however, calves reared on WS spent more time self-grooming than calves reared on PG, RC, and SA. During a 20min arena test, running, bucks, jumps, and kicks performed by calves was not affected by rearing substrate. In conclusion, the physiology and behavior of calves reared on PG, RC, and SA was similar to WS, which is considered the preferred rearing substrate to use when rearing calves. Therefore, PG, RC, and SA may be acceptable substrate options when rearing group-housed dairy calves.

Key words: behavior, dairy calf, housing, welfare

\section{INTRODUCTION}

The health and welfare of dairy calves during the first few weeks of life can be affected by housing and management practices. One important aspect of calf management is the rearing substrate used as this can affect calf growth, hygiene, health, and behavior. Several rearing substrates used in calf rearing systems have been evaluated in the literature including concrete, granite fines, rice hulls, rubber mats, sand (SA), straw, stones, and sawdust/wood shavings (Panivivat et al., 2004; Hänninen et al., 2005; Hill et al., 2011; Camiloti et al., 2012; Sutherland et al., 2013; Worth et al., 2015). Rearing substrate can affect calf cleanliness (Panivivat et al., 2004), weight gain and the incidence of diarrhea/ scours (Panivivat et al., 2004; Hill et al., 2011), skin surface temperature (Sutherland et al., 2013), acute phase protein concentrations (Alsemgeest et al., 1995), and the level of bacterial contamination (Panivivat et al., 2004). However, studies investigating the effect of rearing substrate on calf health, physiology, and behavior have predominantly focused on individually housed or pair-housed calves.

Dairy calves are commonly housed individually during the first weeks of life to reduce risk of infectious 
disease transmission among individuals. However, emerging evidence suggests that pair or group housing of calves has several benefits including reducing labor requirements and costs (Costa et al., 2015), increasing weight gains and intake of solid feed (Costa et al., 2015; Jensen et al., 2015), allowing calves to perform social behaviors important for development, and giving them more useable space (Jensen et al., 1998; Færevik et al., 2007; Costa et al., 2016). Due to this emerging change in calf management practices, it is necessary to evaluate the effect of different rearing surfaces on the health, physiology, and behavior of calves reared in group housing systems.

Organic materials, such as wood shavings (WS) and straw, are commonly used as rearing substrates for calves. Panivivat et al. (2004) found that calves reared on rice hulls, wheat straw, or WS had higher cleanliness scores than calves reared on granite fines or SA. Calves reared on WS also had higher skin surface temperatures than calves reared on stones, which may indicate increased thermal comfort (Sutherland et al., 2013). In addition, calves reared on rice hulls spent more time self-grooming than calves reared on long wheat straw or WS (Panivivat et al., 2004), and calves reared on WS spent more time lying and performing locomotor play in the home pen than calves reared on stones (Sutherland et al., 2013). Rearing substrate may also affect the motivation of animals to perform specific behaviors if those behaviors are restricted in the home pen; for example, calves reared on stones performed more play behavior than calves reared on WS when removed from the home pen and put into an arena test (Sutherland et al., 2014a). Dairy calves also show a clear preference for lying on dry WS and an aversion to lying on bare concrete (Camiloti et al., 2012) and prefer lying on WS than on SA (Worth et al., 2015). However, some organic substrates are becoming difficult or expensive for farmers to obtain, have higher moisture absorbent properties, and have higher bacteria contamination (Panivivat et al., 2004; Sutherland et al., 2014b). Therefore, rearing substrates that are easily accessible and that maintain good calf health and welfare need evaluating. Sand is commonly used as a lying surface for adult dairy cattle in free-stall systems, pea gravel (PG) has good drainage properties, and rubber chip (RC) has the advantage of being a recycled product with high insulation properties. Therefore, the objective of this study was to compare the health, physiology, and behavior of group-housed calves reared on WS with those reared on alternatives surfaces (SA, PG, and $\mathrm{RC})$. It was predicted that the health, physiology, and behavior of group-housed calves reared on PG, RC, or $\mathrm{SA}$ would be similar to calves reared on WS.

\section{MATERIALS AND METHODS}

\section{Animals, Housing, and Feeding}

This study was conducted between July and September (Southern hemisphere winter) 2013 at the AgResearch dairy research farm, South Waikato $\left(175^{\circ}\right.$ $\left.1800^{\prime} \mathrm{E},-38^{\circ} 0300^{\prime} \mathrm{S}\right)$, New Zealand. All procedures involving animals were approved by the AgResearch Ruakura Animal Ethics Committee (\#12961) under the New Zealand Animal Welfare act 1999.

Eighty Friesian-cross dairy heifer calves were used in the study over 5 replicates. The calves were separated from their dams within $24 \mathrm{~h}$ of birth and transported to the farm's calf rearing facility. The calf rearing facility had solid dirt floors and walls on all 4 sides. The walls were either solid or covered with shade cloth to reduce exposure from the wind. Calves were kept in group pens (15 calves per pen, $3 \mathrm{~m} \times 7 \mathrm{~m}$ ) with floors covered with wood chips before being moved to experimental pens at approximately $5 \mathrm{~d}$ of age. Experimental pens $(2.5 \mathrm{~m}$ $\times 2.6 \mathrm{~m}$ ) were located in the middle of the facility and were separated by wooden panel fences that allowed auditory, visual, olfactory, and some tactile contact between animals in adjoining pens. The floor of the experimental pens was covered in 1 of 4 substrates: (1) WS (Pinus radiata with an average particle size of 10 $\mathrm{mm}$, (2) SA, (3) RC (with a particle size of 4 to $7 \mathrm{~mm}$, Pacific Rubber, Auckland, New Zealand), and (4) PG (with an approximate diameter of 3-5 mm, Mangatangi River Rock Ltd., Auckland, New Zealand). Rearing substrates were laid over dirt floors at a depth of approximately $40 \mathrm{~cm}$. Substrates had not been used before the start of the study. Wood shavings and SA pens were topped up with dry, clean substrate when pens became damp (approximately once a week), following the normal operating procedure at the farm. However, $\mathrm{PG}$ and $\mathrm{RC}$ were not cleaned during the experimental period as these pens remained relatively clean and dry throughout the experimental period.

Calves were individually fed $2 \mathrm{~L}$ of colostrum twice a day at 0800 and $1600 \mathrm{~h}$ for the first $4 \mathrm{~d}$ after birth. Thereafter, the equivalent amount of milk replacement was offered (Calf milk replacer, Milligans, Oamaru, New Zealand) using a 5-teat milk feeder (Calfateria series, MM5, Stallion Plastic Ltd., Palmerston North, New Zealand), which was removed after each feeding. Additionally, calves were given ad libitum access to TOPCALF Formula 20 (Inghams Feed \& Nutrition, Hamilton, New Zealand) consisting of $20 \%$ CP, $5 \%$ crude fat, and $7 \%$ crude fiber, in plastic troughs (310 $\mathrm{mm}$ width $\times 770 \mathrm{~mm}$ length $\times 260 \mathrm{~mm}$ depth) attached to the side of the pen. Water was also provided 
ad libitum in plastic troughs $(350 \mathrm{~mm}$ width $\times 300$ $\mathrm{mm}$ length $\times 200 \mathrm{~mm}$ depth) attached to the side of the pen.

\section{Experimental Design}

At approximately $5 \mathrm{~d}$ of age, 80 calves $(38.5 \pm 4.28$ $\mathrm{kg}$ ) were allocated to 1 of 4 treatments (calves reared on WS, SA, RC, or PG; $\mathrm{n}=20$ calves/treatment) and then moved into 1 of 20 experimental pens ( $\mathrm{n}=$ 4 calves/pen). Treatments were balanced for calf age and BW. The study was replicated 5 times with calves for each replicate moved into experimental pens at the same time ( $\mathrm{n}=16$ calves/replicate). Replicates were run approximately $1 \mathrm{wk}$ apart. In each replicate, all 4 treatments were equally represented. Calves remained in the experimental pens until 6 wk of age.

Environmental Conditions. Air temperature and relative humidity inside the calf rearing facility were measured continuously during the trial period using weather stations (Vantage Pro2 Plus, David Instrument Corp., Hayward, CA). Data were recorded every 10 min over a 24-h period during wk 1, 3, and 6 of the study period at the same time that behavior was recorded.

Substrate samples were collected from 3 locations within each of the experimental pens at the end of wk 1,3 , and 6 of the study period to calculate DM content (\%). Substrate samples were weighed before drying at $95^{\circ} \mathrm{C}$ in a forced draft oven for $72 \mathrm{~h}$, before reweighing to determine DM content.

BW, Cleanliness, and Health. Before being moved into experimental pens and at 3 and 6 wk of age, calves were weighed and inspected by a veterinarian for clinical signs of disease and leg injuries and abnormalities.

A cleanliness score was recorded for all calves weekly using a scoring system adapted from Panivivat et al. (2004). Briefly, $1=$ calf is clean (no dirt/manure present around the thighs or body, only manure present at lower ends of legs), $2=\mathrm{dirt} /$ manure is present around the tail head region and back of calf, $3=$ dirt/manure is present around the tail head region, thighs, or legs of the calf, and $4=$ dirt/manure is present on the thighs, legs, and tail head region of the calf.

A modified version of the fecal fluidity score developed by Larson et al. (1977) was used, where $1=$ normal, $2=$ soft and spreads slightly, $3=$ runny and spreads moderately, and $4=$ watery (severe scours). Scores were given at 3 and 6 wk of age at the same time as fecal samples were collected for bacterial counts. A single observer scored all calves on every occasion.

Skin Surface and Vaginal Temperatures. During wk 1,3 , and 6 of the study, temperature data loggers (Thermochron ibutton, model DS1921H-F5\#, range 15.0-46. $0^{\circ} \mathrm{C}$, accuracy $\pm 1^{\circ} \mathrm{C}$, Embedded Data Systems,
Lawrenceburg, KY) were attached to calves to continuously measure skin surface temperature. Data loggers were attached to the chest of the calf, just behind the front legs. Hair was removed from the area and loggers were secured with a $5-\mathrm{cm}^{2}$ elastic adhesive bandage (Elastoplast, BSN Medical Inc., Hamburg, Germany). The bandages were further secured in the corners with glue (KAMAR, Livestock Improvement Corporation, Hamilton, New Zealand). Data loggers were set to record temperatures every $10 \mathrm{~min}$ for $24 \mathrm{~h}$ during the same period that behavior was recorded.

During wk 1, 3, and 6 of the study, temperature data loggers (Thermochron ibutton, model DS1922L-F5\#, range $-40.0-85^{\circ} \mathrm{C}$, accuracy $\pm 0.5^{\circ} \mathrm{C}$, Embedded Data Systems) were used to monitor vaginal temperature as an estimate of core temperature. Temperature data loggers were placed inside a cut-off finger of a latex glove with a length of fishing line (approximately $12 \mathrm{~cm}$ in length) attached at one end to allow easier removal of the temperature logger at the end of the recording period. The temperature logger was disinfected with iodine, then positioned in the vulva past the vagina sphincter. Data loggers were set to record temperature every $10 \mathrm{~min}$ for $24 \mathrm{~h}$ during the same period that behavior was recorded.

Physiological Responses. Blood samples were obtained at 1, 3, and $6 \mathrm{wk}$ of age (approximately 3 $\mathrm{h}$ after morning feeding) by jugular venipuncture and collected into evacuated tubes that contained sodium fluoride, EDTA or no anticoagulant (BD Vacutainer, Franklin Lakes, NJ). Samples containing sodium fluoride were placed immediately on ice and centrifuged within $3 \mathrm{~h}$ at $1,500 \times g(\sim 3,000 \mathrm{rpm})$ for $10 \mathrm{~min}$. Samples in plain evacuated tubes were held at ambient temperature following collection for at least $2 \mathrm{~h}$ to allow serum to separate before centrifugation at 1,500 $\times g(\sim 3,000 \mathrm{rpm})$ for $10 \mathrm{~min}$. Following centrifugation, plasma and serum were aspirated and aliquots stored at $-20^{\circ} \mathrm{C}$ until assayed for cortisol, $\operatorname{IgG}$, and lactate concentrations. Samples containing EDTA were placed immediately on ice and delivered within $3 \mathrm{~h}$ to New Zealand Veterinary Pathology laboratory (Hamilton, New Zealand). Blood smear slides were performed on a Sysmex XT-2000 iV using veterinary software and Sysmex reagents (Sysmex Corporation, Kobe, Japan) for estimation of total white blood cell counts, plasma neutrophils, lymphocytes, hemoglobin, and hematocrit. White blood cell differentials were performed using a standard 100 cell count and the neutrophil to lymphocyte ratio was calculated by dividing the percentage of neutrophils by the percentage of lymphocytes. Cortisol concentrations were measured using a solid phase single antibody radioimmunoassay kit (Coat-a-Count Cortisol, Siemens, Los Angeles, CA). The minimum 
detectable level was $0.5 \mathrm{nmol} / \mathrm{L}$, and inter- and intraassay coefficients of variation were 6.4 and $4.3 \%$, respectively. Lactate concentrations were measured using a colorimetric enzymatic assay and IgG concentrations using a turbidimetric immunoassay performed on the Roche/Hitachi Modular Analytics P800 automated clinical chemistry analyzer (Roche Diagnostics GmBH, Mannheim, Germany).

Escherichia coli Counts. For each calf, shoulder swab samples and fecal samples were collected at 3 and 6 wk of age. The shoulder swab samples were obtained by rubbing a sterile sponge, saturated with $20 \mathrm{~mL}$ of sterile $0.1 \%$ peptone (Fort Richard Laboratories, Auckland, New Zealand) over a $100-\mathrm{cm}^{2}$ area of the shoulder following the AgResearch Micromanual (2005) protocol for swabbing a large surface area. Individual sponges were homogenized by stomaching (Colworth Stomacher 400, Seward Ltd., West Sussex, UK) for 2 min with $180 \mathrm{~mL}$ of sterile milliQ water (Millipore, Billerica, MA). A composite suspension was obtained for each pen by combining an equivalent volume $(30 \mathrm{~mL})$ of each stomached suspension obtained from the 4 calves in the pen. The resultant pen composite suspension was diluted in sterile milliQ water (1:10 and 1:100). Fecal samples were obtained by direct retrieval, and the fecal sample was transferred to individual sterile containers. All samples transported to the laboratory in an insulated box and were analyzed within $24 \mathrm{~h}$ of collection. A composite fecal sample was obtained for each pen by combining $2 \mathrm{~g}$ of feces collected from each calf in the pen. The resultant pen composite feces were diluted in sterile milliQ water $\left(10^{-5}\right.$ and $\left.10^{-7}\right)$.

The number of $E$. coli in the diluted pen composite suspension from the shoulder swabs and in the diluted composite feces were measured by a most probable number method using Colilert/Quantitray 2000 (Idexx Laboratories Inc., Westbrook, ME). The number of $E$. coli/100 mL of composite suspension or number of $E$. coli/100 g of composite feces was obtained from the tables supplied by the manufacturer.

Behavioral Responses. Lying and standing times in the home pen were recorded using Onset Pendant $\mathrm{G}$ accelerometer data loggers (64k, Onset Computer Corporation, Bourne, MA) over a 24 -h period when calves were 1,3 , and 6 wk of age. The accelerometers were programmed to measure leg orientation at 1-min intervals. The accelerometers were placed in a durable fabric pouch and attached on the lateral side of the hind leg above the metatarsophalangeal joint $1 \mathrm{~d}$ before the start of data collection. The pouch was held in position using velcro patches, one sewn to the pouch, the other glued (KAMAR, Livestock Improvement Corporation, Hamilton, New Zealand) to the leg of the calf. The pouch was further held in place by a strap around the leg of the calf. The accelerometers remained on the calves throughout the study period. The data were downloaded using the Onset HOBOware Pro software (Onset Computer Corporation, version 3.4.1), which converted the $g$-force readings into degrees of tilt and further converted to daily summaries of lying behavior using SAS software (SAS Institute Inc., Cary, NC) code designed for this purpose (N. Chapinal, University of Guelph, Ontario, Canada, personal communication). Calf activity variables associated with acceleration and angle displacement included total lying time and number of lying bouts.

Calf behavior (running and self-grooming, described in Table 1) was recorded continuously in the home pen in real time at 30 frames/s for $8 \mathrm{~h}$ during daylight hours using overhead digital handycams (Sony Handycam Camcorder DCR-SX65, Tokyo, Japan) when calves were 1,3 , and $6 \mathrm{wk}$ of age. Prior to recording behavior, individual calves were marked using animal marking paint (Tell-tail paint, FIL New Zealand, Mount Maunganui, New Zealand). The cameras were situated $1.5 \mathrm{~m}$ above the ground, fixed to stands that were attached to the side of the pens. Handycams were fitted with a fisheye (Raynox Digital 0.3x conversion lens, QC-303 Snap-On, Tokyo, Japan) to ensure the entire pen was in view. Video recordings were analyzed over the 8-h period using continuous sampling (Martin and Bateson, 1993) to calculate the time calves spent running and self-grooming (Table 1). Four trained people were used to analyze the video recordings and inter-observer reliability was calculated; percentage of agreement between observers was between 70 and $92 \%$ for all behaviors.

At the end of the study period, calves were tested individually for 20 min in a play arena based on methodology described in Mintline et al. (2012). The test arena was located in the same building and in close proximity to the experimental pens. The arena measured $3.0 \mathrm{~m}$ $\times 15 \mathrm{~m}$ and the floor of the arena was covered in wood chips. The walls of the arena were covered with black plastic to prevent calves from seeing the observers and other calves. All testing took place between 1000 and $1330 \mathrm{~h}$. Testing for each replicate was conducted over 2 consecutive days (2 calves/treatment per d). Calves were moved gently and quietly from their home pen, by 2 experienced handlers, to the arena. Behavior was recorded continuously in real time at 30 frames/s for 20 min using the same handycams as in the home pen. The 20-min recording period started once the calf entered the arena and the gate was closed behind it. Calves were unfamiliar with the arena before the first test. Behaviors scored continuously as frequencies were running, jumping, kicking, and bucking (Table 1). Running was scored as frequency and duration. Running bouts 
separated by a pause of less than $1 \mathrm{~s}$ were considered the same event. All other play behaviors were recorded if they occurred on their own or within a running bout. One experienced observer was used to analyze the video recordings and intra-observer reliability was between 96 and $100 \%$ for all behaviors.

\section{Statistical Analysis}

Data were analyzed by ANOVA using GenStat (13th ed., VSN International Ltd., Hemel Hempstead, UK). Data were transformed where necessary to equalize the variance to better meet the normality assumptions of the analysis. Blood chemistry and neutrophil:lymphocyte data were log-transformed, whereas running and selfgrooming in the home pen and kicks, bucks, and jumps in arena test were square-root transformed.

Initial analyses to compare treatments were done as a split-plot fitting pen in the model, to check if calves within the same pen were less variable than calves in different pens. For BW, hematology, blood chemistry, and behavior in the arena, no significant pen effect was found, so calves were treated as independent. For behavior in the home pen, all tests and standard errors used pen as the experimental unit. All weeks were included in a repeated measures analysis. The hematology repeated measures analysis was for 3-and 6-wk data, with wk-1 data used as a covariate. Untransformed means and standard error of the differences of means are presented with the $P$-value from the transformed analyses. Statistical significance was determined at $P$ $\leq 0.05$ and $0.05<P \leq 0.10$ was considered a tendency.

\section{RESULTS}

\section{Environmental Conditions}

Values for environmental conditions and DM content are summarized by means \pm standard deviation. Dur- ing the entire study period, temperatures and relative humidity inside the calf rearing facility averaged 11.0 $\pm 3.13^{\circ} \mathrm{C}$ and $87.2 \pm 7.78 \%$, respectively. Moisture content of RC, SA, WS, and PG over the study period was $3.4 \pm 1.83,9.3 \pm 5.78,41.9 \pm 13.08$, and $3.3 \pm 1.67 \%$ respectively.

\section{Body Weight, Cleanliness, and Health}

Body weight did not differ among calves reared on $\mathrm{PG}, \mathrm{RC}, \mathrm{SA}$, or WS, regardless of age $(P \geq 0.693$; Table 2).

Values for cleanliness and fecal scores are summarized by means \pm SD. All calves were clean; no calf scored higher than a 2 on the cleanliness score scale regardless of substrate type or age. Cleanliness scores of PG, RC, $\mathrm{SA}$, and WS over the study period were $1.0 \pm 0.13,1.0$ $\pm 0.18,1.0 \pm 0.13$, and $1.0 \pm 0.00$, respectively.

No calf displayed any signs of lameness, leg lesions, injury, or abnormalities at wk 1,3 , or 6 , regardless of substrate type or age. Fecal scores of PG, RC, SA, and WS over the study period were $1.3 \pm 0.72,1.3 \pm 0.69$, $1.3 \pm 0.53$, and $1.2 \pm 0.54$, respectively.

\section{Skin and Vaginal Temperatures}

Rearing substrate influenced skin surface temperature of calves $(P<0.001)$. Over the entire study period, calves reared on PG and SA had lower $(P<0.05)$ skin temperatures than calves reared on $\mathrm{RC}$ or $\mathrm{WS}$, but skin temperature was similar between calves reared on $\mathrm{PG}$ and SA (PG: $32.1 \pm 0.30^{\circ} \mathrm{C}$; RC: $33.3 \pm 0.30^{\circ} \mathrm{C}$; SA: $31.7 \pm 0.30^{\circ} \mathrm{C}$; WS: $\left.32.7 \pm 0.30^{\circ} \mathrm{C}\right)$. However, vaginal temperature did not differ among calves reared on different substrates at 1,3 , or 6 wk of age $(P \geq 0.522$; PG: $39.2 \pm 0.13^{\circ} \mathrm{C}$; RC: $39.2 \pm 0.13^{\circ} \mathrm{C}$; $\mathrm{SA}: 39.3 \pm 0.13^{\circ} \mathrm{C}$; WS: $\left.39.3 \pm 0.13^{\circ} \mathrm{C}\right)$.

Table 1. Description of behaviors

\begin{tabular}{|c|c|}
\hline Behavior & Description \\
\hline \multicolumn{2}{|l|}{ Locomotor play } \\
\hline Buck $^{1}$ & $\begin{array}{l}\text { While the calf is moving, the body ascends from front to back, and one or both hind legs are lifted off the } \\
\text { ground in one rapid movement and extended outward from the body. The hind hooves are raised as high or } \\
\text { higher than the front knees of the forelegs. }\end{array}$ \\
\hline $\mathrm{Jump}^{1}$ & $\begin{array}{l}\text { The } 2 \text { forelegs are lifted off the ground; the front of the body is elevated. Movement is upward but not } \\
\text { forward. The hind legs may be lifted off the ground. }\end{array}$ \\
\hline Kick & $\begin{array}{l}\text { One or both hind legs are lifted off the ground and extended outward from the body. The calf can be } \\
\text { stationary or moving. }\end{array}$ \\
\hline Running $^{2}$ & $\begin{array}{l}\text { Includes trotting (2-beat gait), cantering (3-beat gait), and galloping (fast } 4 \text {-beat gait) with forward or } \\
\text { sideways movement. Lasting longer than } 1 \mathrm{~s} \text { in real time. Pauses less than } 1 \mathrm{~s} \text { were considered within the same } \\
\text { running event. }\end{array}$ \\
\hline Self-grooming $^{3}$ & $\begin{array}{l}\text { The calf's tongue is out of its mouth and in contact with its own body. Calf may scratch its body with its } \\
\text { hind leg. Pauses less than } 1 \mathrm{~s} \text { are considered within the same grooming event. }\end{array}$ \\
\hline
\end{tabular}

\footnotetext{
${ }^{1}$ Definition based on the ethogram presented in Jensen et al., 1998.

${ }^{2}$ Definition based on the ethogram presented by Mintline et al., 2012.

${ }^{3}$ Definition based on the ethogram presented by Jensen and Budde, 2006.
} 
Table 2. Body weight, hematology, and blood chemistry of calves reared on pea gravel, rubber chips, sand, or wood shavings over a 6-wk study period $(\mathrm{n}=20$ calves/rearing substrate)

\begin{tabular}{|c|c|c|c|c|c|c|}
\hline Item & \multicolumn{4}{|c|}{ Rearing substrate } & $\mathrm{SED}^{1}$ & $P$-value \\
\hline 1 wk of age & 39.0 & 38.7 & 38.3 & 38.0 & 1.35 & 0.893 \\
\hline 3 wk of age & 42.3 & 41.4 & 42.0 & 42.2 & 1.59 & 0.932 \\
\hline 6 wk of age & 57.6 & 56.9 & 56.2 & 58.7 & 2.08 & 0.693 \\
\hline \multicolumn{7}{|l|}{ Hematology } \\
\hline Lymphocytes (\%) & 61.6 & 61.2 & 59.3 & 58.0 & 2.57 & 0.475 \\
\hline Neutrophil:lymphocyte & 0.53 & 0.54 & 0.63 & 0.64 & 0.085 & 0.393 \\
\hline Hemaglobin $(\mathrm{g} / \mathrm{L})$ & 108 & 109 & 109 & 110 & 2.0 & 0.789 \\
\hline Hematocrit (L/L) & 0.33 & 0.33 & 0.33 & 0.33 & 0.006 & 0.650 \\
\hline \multicolumn{7}{|l|}{ Blood chemistry } \\
\hline Cortisol (ng/mL) & 3.2 & 5.4 & 5.1 & 6.2 & 1.42 & 0.524 \\
\hline $\operatorname{IgG}(\mathrm{mg} / \mathrm{dL})$ & 1,142 & 1,133 & 1,212 & 1,212 & 40.7 & 0.343 \\
\hline
\end{tabular}

${ }^{1} \mathrm{SED}=$ standard error of the difference.

\section{Physiological Responses}

Hematology values (white blood cells counts, neutrophil and lymphocyte percentages, hemoglobin, and hematocrit) of calves were similar among rearing substrates at 3 and 6 wk after adjusting for wk- 1 levels $(P$ $\geq 0.317$; Table 2).

Over the entire study period, cortisol, IgG, and lactate concentrations were similar among calves regardless of rearing substrate $(P \geq 0.303$; Table 2$)$.

\section{Escherichia coli Counts}

Escherichia coli recovered from a surface area of 100 $\mathrm{cm}^{2}$ on the shoulder of each calf was affected by rearing substrate, with more $E$. coli recovered from calves reared on WS than $\mathrm{PG}, \mathrm{RC}$, or $\mathrm{SA}$ at 3 and 6 wk of age $(P \leq 0.031$; Table 3$)$. Fecal $E$. coli counts were not affected by rearing substrate at 3 or 6 wk of age $(P \geq$ 0.290; Table 3).

\section{Behavioral Responses}

In the home pen, rearing substrate did not influence lying times $(P \geq 0.278)$ at 1,3 , or 6 wk of age; however, calves reared on WS performed more lying bouts than calves reared on PG $(P=0.001)$ or SA $(P=0.001)$ over the 6 -wk study period (Table 4 ). During the 8-h daylight period, the time calves spent self-grooming was similar $(P>0.05)$ among rearing substrates, but rearing substrate affected $(P=0.05)$ the frequency of self-grooming with WS calves performing more selfgrooming bouts than calves reared on PG, RC, and SA over the 6 -wk study period (Table 4 ). The duration and frequency of running performed by calves were similar $(P>0.05)$ among rearing substrates over the 6 -wk study period (Table 4).

During a 20-min arena test, running (frequency and duration) and the frequency of bucks, jumps, and kicks performed by calves were not affected by rearing substrate in the home pen $(P>0.05$; Table 4$)$.

Table 3. Number of Escherichia coli on the shoulder and in the feces of calves reared on pea gravel, rubber chips, sand, or wood shavings at 3 and 6 wk of age $(n=5$ replicates/rearing substrate)

\begin{tabular}{|c|c|c|c|c|c|c|}
\hline \multirow[b]{2}{*}{ Item } & \multicolumn{4}{|c|}{ Rearing substrate } & \multirow[b]{2}{*}{ SEM } & \multirow[b]{2}{*}{$P$-value } \\
\hline & Pea gravel & Rubber chips & Sand & Wood shavings & & \\
\hline \multicolumn{7}{|c|}{ E. coli on calf shoulder $\left(\log _{10} / 100 \mathrm{~cm}^{2}\right)$} \\
\hline 3 wk of age & $3.2^{\mathrm{b}}$ & $3.1^{\mathrm{b}}$ & $3.5^{\mathrm{b}}$ & $4.1^{\mathrm{a}}$ & 0.21 & 0.031 \\
\hline 6 wk of age & $3.1^{\mathrm{b}}$ & $3.0^{\mathrm{b}}$ & $2.9^{\mathrm{b}}$ & $3.8^{\mathrm{a}}$ & 0.17 & 0.015 \\
\hline \multicolumn{7}{|c|}{ E. coli in calf feces $\left(\log _{10} / 100 \mathrm{~g}\right)$} \\
\hline 3 wk of age & 10.5 & 10.0 & 10.4 & 10.6 & 0.23 & 0.290 \\
\hline
\end{tabular}

${ }^{\mathrm{a}, \mathrm{b}}$ Means within rows with different superscripts differ at $P<0.05$. 
Table 4. Behaviors performed by calves reared on pea gravel, rubber chips, sand or wood shavings in the home pen and in a 20 -min arena test at 6 wk of age $(n=20$ calves/rearing substrate)

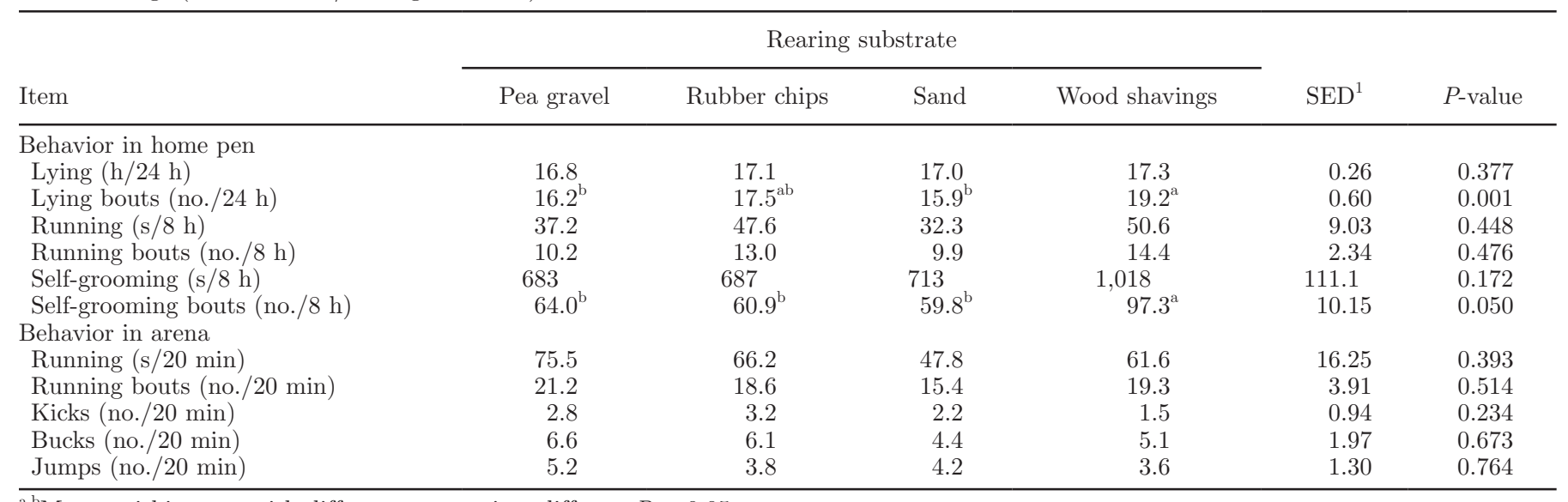

${ }^{\mathrm{a}, \mathrm{b}}$ Means within rows with different superscripts differ at $P<0.05$.

${ }^{1} \mathrm{SED}=$ standard error of the differences of means.

\section{DISCUSSION}

Dairy calves are commonly reared on organic substrates such as WS or straw, however, some organic substrates are becoming difficult or expensive (or both) for farmers to obtain, so it is necessary to evaluate different substrates for rearing group-housed calves that maintain good calf health and welfare. However, limited scientific information is currently available regarding the welfare implications of rearing group-housed calves on different substrates. In the present study, we measured growth, health, physiology, and behavior to investigate the effect of different rearing substrates (SA, $\mathrm{PG}$, and $\mathrm{RC}$ ) on the welfare of group-housed calves and to compare these measures with calves reared on WS. Calves reared on WS had higher E. coli counts recovered from their coats, performed more lying and self-grooming bouts, and had higher skin surface temperatures than calves reared on PG or SA. However, overall growth and health were similar among calves reared on all 4 substrates.

Calves reared on PG and SA had lower skin surface temperatures; however, lower skin surface temperature was not related to lower vaginal temperatures, which was used as an indirect measure of core temperature. Gonzalez-Jimenez and Blaxter (1962) found that calves fed an allowance of $10 \%$ of BW (similar to calves in the present study) had a lower critical ambient temperature threshold of $13^{\circ} \mathrm{C}$ at 1 wk of age; hence, 1-wk-old calves in the present study were experiencing temperatures below the lower critical threshold. In addition, Gonzalez-Jimenez and Blaxter (1962) found exposure to cold ambient temperatures caused piloerection, followed by vasoconstriction, and then shivering at $10^{\circ} \mathrm{C}$ in calves. In the present study, neither piloerection or shivering were observed; however, the lower skin surface temperature of $\mathrm{PG}$ and $\mathrm{SA}$ calves suggests that these animals were using vasoconstriction to facilitate thermoregulation. Therefore, rearing calves on surfaces with lower insulation properties, such as PG or SA, in colder environmental conditions could potentially result in calves experiencing thermal discomfort. Conversely, rearing calves on PG or SA may be beneficial in hotter climates to enable heat conduction and support calf thermoregulation.

Rearing substrate can influence the time calves spend self-grooming; calves reared on rice hulls spent more time self-grooming than calves reared on long wheat straw or WS (Panivivat et al., 2004). In the present study, calves reared on WS performed more self-grooming bouts than calves reared on the other substrates. Panivivat et al. (2004) suggested that rice hulls adhered more to the coat of the calves, causing them to perform more self-grooming, which could have been due to the higher moisture content of rice hulls than wheat straw or WS. Correspondingly, in the present study, WS had the highest moisture content of all substrates evaluated so the WS may have adhered to the coat of the calves more than the other substrates. However, all calves were relatively clean and did not score higher than a 2 on the cleanliness score scale. Alternatively, increased self-grooming could be associated with nonnutritive activity. Calves may be more likely to manipulate and ingest $\mathrm{SW}$ than $\mathrm{SA}, \mathrm{RC}$, or PG; however, this behavior was not measured in the present study.

In the present study, E. coli counts recovered from the shoulder of calves reared on WS were higher than on all other substrates, although cleanliness scores were similar among all calves. Lying times were similar among all treatments, hence increased $E$. coli counts were not 
likely due to increased contact between the calf and rearing substrate. It has been reported (LeJeune and Kauffman, 2005) that a serotype of E. coli (O157:H7) persisted in higher concentrations in used WS than in used SA. In this study WS had the highest moisture content, which could have affected the result, but LeJeune and Kauffman (2005) attributed their result to the higher nutrient content (i.e., OM available to support bacterial growth and survival) of WS compared with SA. In this study WS would have had a higher nutrient content than the other substrates $(\mathrm{PG}, \mathrm{RC}$, or SA). However, our results, which also showed that the E. coli counts on calf shoulders decreased for all bedding materials (including WS) during the course of the study, also did not find that the use of WS was accompanied by any illness among the calves.

Calves spent on average $17 \mathrm{~h}$ lying per day and lying times were similar among calves on all substrates, in the present study. These lying times are similar to calves reared on a range of substrates (Panivivat et al., 2004; Worth et al., 2015). Worth et al. (2015) found that the calves housed on WS spent more time lying than calves on SA or stones and attributed this to the softness/compressibility of WS. The similar lying times of calves on all 4 substrates evaluated in this study may suggest that calves found all these substrates relatively comfortable. However, calves reared on WS performed more lying bouts than calves reared on PG or SA. Conversely, Sutherland et al. (2013) and Worth et al. (2015) found no difference in the number of lying bouts irrespective of rearing substrate. Lying behavior has been used as an indicator of dairy cow comfort and used to evaluate different flooring surfaces (Haley et al., 2001; Norring et al., 2008; Tucker et al., 2009). In dairy cows, greater number of lying bouts has been associated with hardness of the flooring (Haley et al., 2001); however, it is unlikely that this is the cause of increased lying bouts of WS calves in the present study. Alternatively, increased lying bouts may be associated with reduced comfort due to the higher moisture content of the WS. Irrespective of differences in lying bouts, Worth et al. (2015) found that calves had a clear preference for lying on WS when given free choice of WS, RC, SA, and stones, and also when presented with WS in a pairwise choice period. The very strong preference of calves to lie on WS suggests that rearing calves on this substrate is preferable to alternative substrates such as RC and SA.

Play behavior has been linked with good welfare and positive affective states in several species (Held and Śpinka, 2011). Rearing substrate has been shown to affect play behavior of calves in the home pen, with calves housed on WS and RC spending more time running than calves housed on stones (Worth et al., 2015).
In addition, Sutherland et al. (2013) found that calves reared on stones spent less time performing play behavior in comparison to calves reared on WS in the home pen, and Sutherland et al. (2014a) found that when removed from the home pen and put into an arena test, calves reared on stones performed more play behavior than calves reared on WS. Increased performance of a particular behavior, also referred to as a rebound effect, can sometimes occur after a period of behavioral restriction (Jensen, 1999), hence calves reared on stones may have been more motivated to play in an arena due to restricted ability to play in the home pen. However, in the present study rearing substrate in the home pen did not appear to influence the performance of play behavior in an arena test, suggesting that none of the substrates evaluated restricted the ability of calves to play in the home pen. To support this, during the 8-h daylight period, calves on all substrates spent a similar time running in the home pen.

Body weights were similar among calves reared on different rearing substrates at 1,3, and 6 wk of age in the present study. Body weight was also similar among calves reared on granite fines, SA, rice hulls, wheat straw, or WS from birth until 6 wk of age (Panivivat et el., 2004) and between calves reared on WS or stones from 1 to 6 wk of age (Sutherland et al., 2013). In addition, no differences in signs of lameness, leg lesions, injury, or abnormalities were found among calves reared on different substrates in the present study. Sutherland et al. (2014b) observed hair loss on the knees and hock region of calves reared on stones for $6 \mathrm{wk}$ and suggested that this was caused by the rubbing of the hair against the hard surface of the stones when calves knelt to lie down. In the present study, it does not appear as though any of the substrates had a detrimental effect on growth or were abrasive enough to cause hair loss or leg injuries.

To evaluate the effect of rearing substrate on calf health and welfare, several blood hematological and chemistry parameters were measured in this study; however, rearing substrate had no effect on any of these measures. Similarly, rearing substrate had no effect on IgG (Panivivat et al., 2004) and cortisol (Alsemgeest et al., 1995; Panivivat et al., 2004; Sutherland et al., 2014b) concentrations in calves. Therefore, none of the substrates evaluated in this study appeared to positively or negatively affect measures of calf health and welfare as compared with WS.

In the present study, a cost-benefit analysis was not conducted comparing the different rearing substrates tested, but availability, practicality and cost are important factors when considering rearing surface options. Practically, the RC, even though a recycled product, may not provide a good solution for farmers as it is 
expensive due to the need to thoroughly remove the imbedded metal wire from the tires using a magnet, and cleaning or disposing of dirty material could be challenging. Organic substrates can be composted, but they are becoming difficult or expensive (or both) for farmers to obtain in some areas, have higher moisture absorbent properties, and have higher bacteria contamination. Both SA and PG are relatively cheap and can provide good drainage, but do not have the insulation properties of organic materials and RC.

In conclusion, the health, physiology, and behavior of calves reared on PG, RC, SA, and WS were similar; therefore PG, RC, and SA may be acceptable options for rearing substrates for group-housed dairy calves. However, 2 other factors that are important when considering rearing surface options for calves are (1) calf substrate preference and (2) practicality of the substrate.

\section{ACKNOWLEDGMENTS}

The authors thank AgResearch staff Suzanne Dowling, Rose Greenfield, Frances Huddart, Jessica Boersen, and Gemma Lowe and the AgResearch Tokanui farm staff, as well as Chloé Picchiottino from the Institut National Supérieur des Sciences Agronomiques, de l'Alimentation et de l'Environnement. AgResearch also gratefully acknowledges that this study was funded by the New Zealand Ministry of Business, Innovation and Employment and New Zealand dairy farmers through DairyNZ.

\section{REFERENCES}

AgResearch Micromanual. 2005. The Meat Industry Microbiological Methods Manual. 4th ed. J. Nills, ed. AgResearch, Hamilton, New Zealand.

Alsemgeest, S. P. M., I. E. Lambooy, H. K. Wierenga, S. J. Dieleman, B. Meerkerk, A. M. van Ederen, and T. A. Niewold. 1995. Influence of physical stress on the plasma concentration of serum amyloid-A (SAA) and haptoglobin (HP) in calves. Vet. Q. 17:9-12.

Camiloti, T. V., J. A. Fregonesi, M. A. G. von Keyserlingk, and D. M. Weary. 2012. Short communication: Effects of bedding quality on the lying behavior of dairy calves. J. Dairy Sci. 95:3380-3383.

Costa, J. H. C., R. K. Meagher, M. A. G. von Keyserlingk, and D M. Weary. 2015. Early pair housing increases solid feed intake and weight gains in dairy calves. J. Dairy Sci. 98:6381-6386.

Costa, J. H. C., M. A. G. von Keyserlingk, and D. M. Weary. 2016. Invited review: Effects of group housing of dairy calves on behavior, cognition, performance, and health. J. Dairy Sci. 99:2453-2467.

Færevik, G., I. L. Andersen, M. B. Jensen, and K. E. Bøe. 2007. Increased group size reduces conflicts and strengthens the preference for familiar group mates after regrouping of weaned dairy calves (Bos taurus). Appl. Anim. Behav. Sci. 108:215-228.
Gonzalez-Jimenez, E., and K. L. Blaxter. 1962. The metabolism and thermal regulation of calves in the first month of life. Br. J. Nutr. $16: 199-212$.

Haley, D. B., A. M. de Passillé, and J. Rushen. 2001. Assessing cow comfort: Effects of two floor types and two tie stall designs on the behaviour of lactating dairy cows. Appl. Anim. Behav. Sci. 71:105-117.

Hänninen, L., A. M. de Passillé, and J. Rushen. 2005. The effect of flooring type and social grouping on the rest and growth of dairy calves. Appl. Anim. Behav. Sci. 91:193-204.

Held, S. D. E., and M. Špinka. 2011. Animal play and animal welfare. Anim. Behav. 81:891-899.

Hill, T. M., H. G. Bateman, J. M. Aldrich, and R. L. Schlotterbeck. 2011. Comparisons of housing, bedding, and cooling options for dairy calves. J. Dairy Sci. 94:2138-2146.

Jensen, M. B. 1999. Effects of confinement on rebounds of locomotor behaviour of calves and heifers, and the spatial preferences of calves. Appl. Anim. Behav. Sci. 62:43-56.

Jensen, M. B., and M. Budde. 2006. The effects of milk feeding method and group size on feeding behavior and cross-suckling in grouphoused dairy calves. J. Dairy Sci. 89:4778-4783.

Jensen, M. B., L. R. Duve, and D. M. Weary. 2015. Pair housing and enhanced milk allowance increase play behavior and improve performance in dairy calves. J. Dairy Sci. 98:2568-2575.

Jensen, M. B., K. S. Vestergaard, and C. C. Krohn. 1998. Play behaviour in dairy calves kept in pens: The effect of social contact and space allowance. Appl. Anim. Behav. Sci. 56:97-108.

Larson, L. L., F. G. Owen, J. L. Albright, R. D. Appleman, R. C. Lamb, and L. D. Muller. 1977. Guidelines toward more uniformity in measuring and reporting calf experimental data. J. Dairy Sci. 60:989-991.

LeJeune, J. T., and M. D. Kauffman. 2005. Effect of sand and sawdust bedding materials on the fecal prevalence of Escherichia coli O157:H7 in dairy cows. Appl. Environ. Microbiol. 71:326-330.

Martin, P., and P. Bateson. 1993. Measuring Behaviour. An Introductory Guide. 2nd ed. Cambridge University Press, Cambridge, UK.

Mintline, E. M., S. L. Wood, A. M. de Passillé, J. Rushen, and C. B. Tucker. 2012. Assessing calf play in an area test. Appl. Anim. Behav. Sci. 141:101-107.

Norring, M., E. Manninen, A. M. de Passillé, J. Rushen, L. Munksgaard, and H. Saloniemi. 2008. Effects of sand and straw bedding on the lying behavior, cleanliness, and hoof and hock injuries of dairy cows. J. Dairy Sci. 91:570-576.

Panivivat, R., E. B. Kegley, J. A. Pennington, D. W. Kellogg, and S. L. Krumpelman. 2004. Growth performance and health of dairy calves bedded with different types of materials. J. Dairy Sci. $87: 3736-3745$.

Sutherland, M. A., M. Stewart, and K. E. Schütz. 2013. Effects of two substrate types on the behaviour, cleanliness and thermoregulation of dairy calves. Appl. Anim. Behav. Sci. 147:19-27.

Sutherland, M. A., G. M. Worth, K. E. Schütz, and M. Stewart. 2014a. Rearing substrate and space allowance influences locomotor play behaviour of dairy calves in an arena test. Appl. Anim. Behav. Sci. 154:8-14.

Sutherland, M. A., G. M. Worth, and M. Stewart. 2014b. The effect of rearing substrate and space allowance on the behavior and physiology of dairy calves. J. Dairy Sci. 97:4455-4463.

Tucker, C. B., D. M. Weary, M. A. G. von Keyserlingk, and K. A Beauchemin. 2009. Cow comfort in tie-stalls: Increased depth of shavings or straw bedding increases lying time. J. Dairy Sci 92:2684-2690.

Worth, G. M., K. E. Schütz, M. Stewart, V. Cave, M. Foster, and M. A. Sutherland. 2015. Dairy calves' preference for rearing substrate. Appl. Anim. Behav. Sci. 168:1-9. 